\title{
Transforming Cardiovascular Disease Prevention in Women: Time for the Pygmalion Construct to End
}

\author{
Nanette K. Wenger \\ Emory University School of Medicine, and Emory Heart and Vascular Center, Atlanta, Ga., USA
}

\author{
Key Words \\ Cardiovascular disease $\cdot$ Gender-specific factors $\cdot$ Risk \\ reduction
}

\begin{abstract}
The transformation of cardiovascular disease prevention for women must address that a number of nontraditional atherosclerotic cardiovascular disease risk factors are unique to or predominant in women. As well, many traditional atherosclerotic cardiovascular disease risk factors impart differential risks for women and for men. Gender-specific risk assessment and management have the potential to improve atherosclerotic cardiovascular disease outcomes in women.
\end{abstract}

(c) 2014 S. Karger AG, Basel

In George Bernard Shaw’s 1912 play 'Pygmalion' [1], subsequently adapted for the stage and screen as 'My Fair Lady', the protagonist repeatedly asks, 'Why can't a woman be more like a man?' This paper details the rationale for transforming cardiovascular disease (CVD) prevention specifically for women. Three aspects are paramount: - A number of nontraditional atherosclerotic CVD (AS$\mathrm{CVD}$ ) risk factors are unique to or predominant in women.

- Traditional ASCVD risk factors impart differential risks for women and for men.

- Gender-specific risk assessment and management have the potential to improve ASCVD outcomes in women.

\section{Magnitude of the ASCVD Problem in Women}

CVD is the leading cause of both mortality and morbidity for women in the USA, with 1 in 4 eventually succumbing to this disease [2-4]. The annual CVD mortality for women is double that of all forms of cancer combined. Relevant for prevention, 2 in 3 women in the USA have at least 1 coronary risk factor, and this percentage increases with older age.

Examination of CVD mortality trends by gender in the USA between 1979 and 2010 [5] affirms that prior to the year 2000, the decline in cardiovascular mortality encompassed solely men. Subsequent to 2000 , there has been a stunning decline in CVD mortality for both women and men, with this improvement being more prominent among women. Nonetheless, more women than men die annually from ASCVD in the USA, although the gender difference is diminishing. This favorable survival trend does not apply to younger women, aged 35-54 years, whose recent cardiovascular mortality has increased by $1 \%$ annually, thereby reversing the pattern of the past 4 decades. Concomitantly, during the past 2 decades, the Framingham Risk Scores of younger women have increased comparably, reflecting, to a great extent, the obesity epidemic and the high prevalence of a sedentary life-

Presented as the Inaugural Nanette K. Wenger Distinguished Lecture at the Third Annual American Society for Preventive Cardiology Cardiovascular Disease Prevention Conference, Boca Raton, Fla., USA, July 2014.

\section{KARGER 125}

(c) 2014 S. Karger AG, Base

0008-6312/14/1301-0062\$39.50/0

E-Mail karger@karger.com

www.karger.com/crd
Nanette K. Wenger, MD, MACC, MACP, FAHA

Professor of Medicine (Cardiology) Emeritus

Division of Cardiology, Emory University School of Medicine

49 Jesse Hill Jr. Drive, SE, Atlanta, GA 30303 (USA)

E-Mail nwenger@emory.edu 
style. These variables highlight the importance of providing preventive cardiovascular screening for women, with ASCVD risk reduction interventions when appropriate.

\section{Disparities among Women}

Women, however, are not a homogeneous population $[2,5,6]$. Amongst African-American women in the USA, almost half have some form of CVD. They have a $34 \%$ prevalence of hypertension with an earlier onset than white women. African-American women are more likely to have metabolic syndrome, and higher rates both of CVD and CVD mortality than white women. Upon hospitalization for acute myocardial infarction, comparison of the risk factor burden according to gender and ethnicity reveals that the greatest risk factor burden is present in black women. In multiple cardiovascular studies, black women are less likely to receive evidence-based therapies.

Hispanic women have a doubled occurrence of diabetes compared to non-Hispanic white women (12.6 vs. $6.5 \%$ ). The health paradox is that, despite the excess of diabetes, Hispanic women have a lower mortality rate and a greater life expectancy than non-Hispanic white women.

\section{Nontraditional Risk Factors Unique to or Predominant among Women}

\section{Pregnancy Complications}

A detailed pregnancy history is an integral component of the assessment of ASCVD risk for women of all ages. Complications of pregnancy including preeclampsia, gestational diabetes, pregnancy-induced hypertension, preterm delivery and low-for-estimated-gestational-age birth weight are all indicators of a subsequent increase in cardiovascular risk [7-11]. It has been suggested that pregnancy is the first stress test a woman undergoes, in that the responses to the cardiovascular and metabolic stresses of pregnancy have the potential for early prediction of a future cardiovascular risk. It remains uncertain whether the complications per se impart the subsequent risk or whether there are shared risk factors, e.g. in the case of preeclampsia and CVD; available data favor the latter concept.

To quantify the adverse impact of preeclampsia and gestational hypertension on subsequent cardiovascular risk, these impart a 3- to 6-fold excess of subsequent hypertension and a doubled risk for ischemic heart disease and stroke. Although preeclampsia subsides with delivery of the placenta, residual endothelial dysfunction persists, and there are reports documenting the association of this endothelial dysfunction with the increased presence of coronary artery calcium.

\section{Oral Contraceptive Therapy}

Oral contraceptive (OCP) therapy does not impart an increase in cardiovascular risk for healthy women who have no traditional cardiovascular risk factors. However, OCP use by women who are cigarette smokers is associated with a 7-fold increase in risk, and hypertensive women are likely to have an elevation in blood pressure in association with OCP therapy. OCP therapy increases the risk of stroke by 1.4- to 2.0-fold, with this risk more prominent among older women [12-16].

Different OCPs impart differential risks. For example, second-generation OCPs, such as levonorgestrel, increase the risk for myocardial infarction whereas fourth-generation OCPs, those with drospirenone, indeed lower blood pressure, although the excess risk of venous thromboembolism remains.

The recommendation is for risk factor assessment and control among women who use OCP therapy.

\section{Hormonal Fertility Therapy}

Just recently, the question has been raised about the impact of hormonal fertility therapy on cardiovascular risk, with the best information available from a Canadian population cohort for the period 1993-2010 [17]. Among these women, successful fertility therapy was associated with a decreased risk of all-cause mortality, nonfatal coronary ischemia, stroke, transient ischemic attack, thromboembolism and heart failure evident in all age and income groups. An unexplored study variable relates to those women who did not have successful fertility therapy; their cardiovascular risk outcomes were unknown, and this raises questions as to whether these data reflect a healthy cohort selection bias.

\section{Menopausal Hormone Therapy}

Clinical trial data have dramatically altered both clinical recommendations and practice regarding the use of menopausal hormone therapy [18-22]. Based on data from the secondary prevention cohort in the Heart and Estrogen Replacement Study (HERS) and the primary prevention study, the Women's Health Initiative, menopausal hormone therapy is not recommended for the primary or secondary prevention of CVD. The 2012 recommendations of the US Preventive Services Task Force identified that menopausal hormone therapy was not recommended for the primary prevention of chronic conditions. 


\section{Systemic Autoimmune Disorders}

Systemic autoimmune disorders are highly prevalent among women, who have an increased risk of coronary heart disease (CHD) and cerebrovascular accident in the presence of systemic autoimmune collagen vascular disorders $[7,23,24]$. CHD is the leading cause of morbidity and mortality among women with systemic lupus erythematosus. There is a 2- to 3-fold increase in myocardial infarction and CVD mortality in women with rheumatoid arthritis. These adverse outcomes warrant screening and intervention for ASCVD risk factors in these populations.

\section{Traditional ASCVD Risk Factors}

\section{Hypertension}

Hypertension is the leading cause of CVD worldwide, but the population-adjusted risk of cardiovascular mortality is greater for women than for men, i.e. 29.0 versus $14.9 \%$ [5, 25-28]. Until the age of 45 years, men are more likely than women to have hypertension, with the trend reversing and women more likely to be hypertensive than men after the age of 65 years. Noteworthy is the impressive correlation of increased body mass index and elevated systolic blood pressure in women; $80 \%$ of women in the USA aged 75 and older have hypertension. Of interest is that this increase in blood pressure with aging is not present in nonindustrialized societies, which likely reflects the relevance of environmental factors on the development of hypertension. Of concern is that only $29 \%$ of elderly women have adequate blood pressure control, in contrast to $41 \%$ of men.

\section{Cigarette Smoking}

Among women in the USA, $16.7 \%$ are cigarette smokers, and smoking is more prevalent among younger women than among younger men [5]. The CVD risk for women who smoke is $25 \%$ greater than that for men smokers [29]. In addition, cigarette smoking triples the risk for the occurrence of myocardial infarction among women. Smoking cessation has been identified as the most cost-effective cardiovascular risk modification in the USA for both genders.

\section{Diabetes Mellitus}

Diabetes confers a greater cardiovascular risk for women than for men, 19.1 versus $10.1 \%$ [26, 30-34]. Compared to diabetic men, diabetic women have a $40 \%$ increase in the risk of incident CHD and a $25 \%$ greater risk of stroke. At the time of initial myocardial infarction, women are more likely than men to have concomitant diabetes mellitus, i.e. 25.5 versus $16.2 \%$.
Diabetes correlates more strongly with CVD mortality in women than in men. It is uncertain whether this is related to increased adiposity, increased abdominal adiposity, insulin resistance or other features in diabetic women. Nonetheless, diabetic women have a far more adverse cardiovascular risk profile than diabetic men, with the diabetic women tending to have clustering of multiple conventional ASCVD risk factors.

Comparing the improvement in survival between the periods 1971-1975 and 1982-1984, diabetic women were the sole subgroup without mortality improvement. There was a decline in mortality among men with and without diabetes and among women without diabetes of 13, 36 and $27.1 \%$, respectively, but the mortality in diabetic women increased by $23 \%$. Related to the emphasis on prevention for women, diabetic women are less likely than diabetic men to be treated for ASCVD risk factors and to have control of these risk factors.

\section{Cholesterol Management}

Hypercholesterolemia imparts the highest population-adjusted CVD risk for women of $47 \%$ and, notably, the benefits obtained from statin therapy are similar for women and men $[26,38]$.

The 2013 ACC/AHA (American College of Cardiology/American Heart Association) guideline on the treatment of blood cholesterol to reduce atherosclerotic cardiovascular risk in adults [36] has occasioned significant changes in the management of dyslipidemia for both genders. These include the use of the new pooled-cohort risk equations, which are gender-specific [35], and lifestyle guidelines (particularly dietary and physical activity) [37] for the lowering of low-density lipoprotein cholesterol, which apply to both genders. The fixed-dose statin therapy for women is based on their risk categorization, and the use of target low-density lipoprotein cholesterol levels is no longer recommended. Importantly, moderate-dose statin therapy is recommended after the age of 75 years for both genders, even with established ASCVD, owing to the paucity of data to support statin recommendations in the elderly population. Nonstatin pharmacotherapies are not recommended for either gender.

The likely results of this guideline on cholesterol management for women will be an increase in indicated statin use, a decrease in inappropriate statin use, a decrease in the use of nonstatin therapies and a decrease in laboratory testing to measure low-density lipoprotein cholesterol.
Wenger 


\section{Obesity}

In 2010, 2 in 3 women in the USA were either obese or overweight. Obesity has as its adverse associations hypertension, dyslipidemia, physical inactivity and insulin resistance $[26,39,40]$. It increases coronary risk more for women than for men, i.e. 64 versus $46 \%$.

To examine this problem with a global perspective, in low- and middle-income nations, there is double the amount of obesity in women than in men. However, in high-income nations, obesity is equivalent among women and men. This highlights the need for addressing control of obesity as a risk factor for women in the developing world.

\section{Physical Inactivity}

Despite the fact that the INTERHEART study showed greater protective effects of exercise for women than for men, $32 \%$ of US adults are physically inactive, more women than men (33.2 vs. $29.9 \%$ ) [26]. Indeed, physical inactivity is the most prevalent risk factor for women, in that a quarter of US women report no regular physical activity and three quarters report less than the recommended amount [37].

Data from the Nurses' Health Study identify a decrease in the development of diabetes in the women who exercised regularly and, among the diabetic women, physical activity decreased the risk of cardiovascular events [41, 42].

Finally, although exercise-based rehabilitation is a class I (level A) recommendation in all ACC/AHA coronary secondary prevention guidelines, women are 55\% less likely to participate than men, with women experiencing lower rates of referral, enrollment and completion of cardiac rehabilitation than their male counterparts.

\section{Depression}

Psychosocial problems, particularly depression, preferentially disadvantage women [43-46]. In the INTERHEART study, psychosocial factors were associated with CVD mortality for women more than for men, i.e. 45.2 versus $28.8 \%$. Such factors included stress at work and at home, financial stress and major life events [26].

Depression is associated with a $1.64 \%$ increase in cardiovascular mortality in women, independent of the severity of the depression. To what extent high-risk behaviors, nonadherence to therapies or depression per se contributeto excess mortality remains uncertain. Nonetheless, mortality is excessive in depressed young women, i.e. younger than 55 years of age, who have established coronary disease.

Transforming CVD Prevention in Women
Depression is also a risk factor for adverse outcomes with acute coronary syndromes [44]. Depression and other psychosocial issues will likely increase with the excessive stress associated with increased global violence and the current global financial instability. The problem is complicated by many cultural taboos, both in the USA and internationally, regarding the access to care for depression and other psychosocial issues.

\section{Aspirin for CVD Prevention}

Aspirin is used as an example of gender-specific issues in pharmacotherapy. Although there are comparable gender recommendations for the use of aspirin for the secondary prevention of ASCVD, aspirin is routinely recommended for the primary prevention of CVD for men but not for women [47].

In the Women's Health Study [48] which involved 38,876 healthy, low-risk women older than 45 years of age, aspirin (a dose of $100 \mathrm{mg}$ every other day) prevented stroke in women younger than 65 years of age, but had no effect on myocardial infarction or cardiovascular death and the potential for gastrointestinal bleeding was significant. For women older than 65 years, there was prevention of stroke, myocardial infarction and cardiovascular death with aspirin administration, but the excess risk of gastrointestinal bleeding was virtually comparable to the protective effect. The recommendation, therefore, is for the individualization of aspirin use for women beyond the age of 65 years.

In contrast, in the Physicians' Health Study, which involved only men, again with aspirin therapy of $100 \mathrm{mg}$ every other day, a benefit was seen for myocardial infarction but not for stroke.

\section{Women's Awareness of CVD}

Currently only $54 \%$ of US women recognize that heart disease is their leading cause of death. Even 15 years after the education and awareness endeavors of the National Heart, Lung, and Blood Institute, the 'Heart Truth' campaign and the American Heart Association's 'Go Red for Women' campaign, there has only been an increase in awareness from 30 to $56 \%$, with a recent plateau in the appreciation of women's CVD risk $[49,50]$. The lack of awareness was greatest in the highest-risk populations, i.e. women from racial and ethnic minorities. There was also a lack of awareness of the burden of CVD for wom- 
en among healthcare providers. This lack of awareness translated into suboptimal application of preventive interventions, less appropriate diagnostic testing, less adherence to evidence-based cardiovascular guidelines and consequent poorer outcomes for women.

The underrepresentation of women in clinical trials and longitudinal studies on CVD and the lack of genderspecific analysis when women were included has limited the scientific database for women and led to uncertainties in clinical practice among healthcare providers. The first step to personalized medicine is incorporating information about sex and gender differences, as highlighted here.

\section{Adherence}

Questions have been raised about the adherence to recommended therapies by gender, with most studies showing a comparable adherence among women and men [51]. The nonadherence characteristics are also comparable by gender and include lower socioeconomic status, lower educational levels and depression. However, a number of barriers to preventive interventions appear specific to women, such as family and caretaking responsibilities, fatigue, stress and lack of personal time.

\section{An International Perspective}

In September 2011, the United Nations (UN) held a summit on noncommunicable diseases (NCDs), only the second time in history that a UN summit on health issues has been convened [52]. The highlights relating to women identified gender disparity with regard to risk and the access to diagnosis and treatment, showing the link of this gender disparity with the empowerment of women and the education of girls. In 2008, 9,127,416 cardiovascular deaths occurred in women worldwide, representing $33.3 \%$ of all deaths in women. The conclusions of the UN summit were that NCDs, in particular CVD, adversely impact women's contributions to society in both their productive and reproductive roles and as consumers and providers of health care. The emphasis was on the vulnerability of women, who represent $60 \%$ of the world's poor and two thirds of illiterate adults.

A follow-up to the UN summit addressed the programs, policies and national plans for CVD prevention, targeting women. The 65th World Health Assembly in May 2012 in Geneva adopted a broad target of a reduction of $25 \%$ in premature mortality from NCDs by 2025 . The

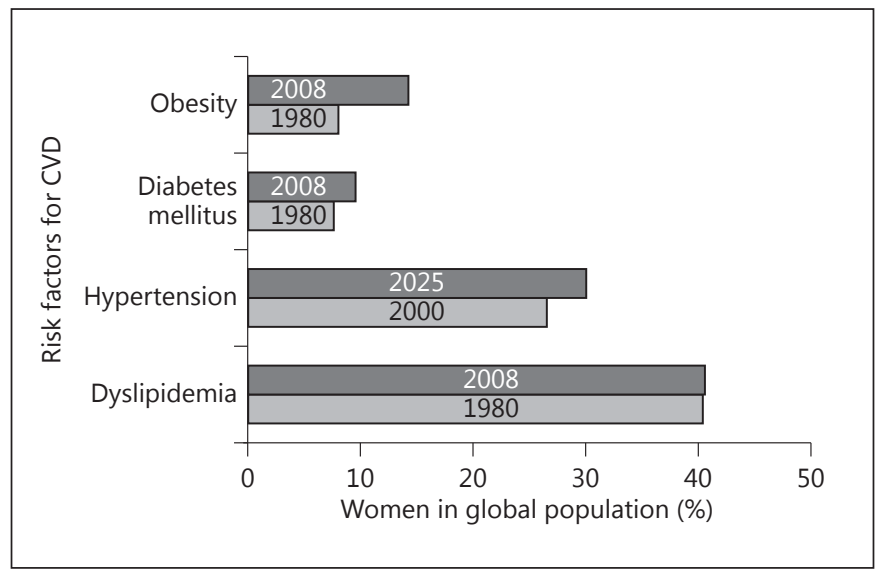

Fig. 1. Estimated and calculated global temporal trends among women for significant cardiovascular risk factors over a period of 20-25 years. Published with permission from Gupta and Wenger [53].

World Heart Federation and the NCD Alliance used targeted advocacy to insure that NCDs were recognized as the major cause of poverty, a barrier to economic development and a global emergency. At the 66th World Health Assembly in 2013, 9 targets and 25 indicators were adopted. The 9 voluntary global NCD targets were: a $25 \%$ reduction in premature mortality from NCDs, $80 \%$ coverage of essential NCD medicines and technologies, 50\% coverage of drug therapy and counseling, a 25\% reduction in raised blood pressure, a $30 \%$ reduction in tobacco use, a $30 \%$ reduction in salt/sodium intake, a $10 \%$ reduction in physical inactivity and a $10 \%$ reduction in the harmful use of alcohol. A global monitoring framework was established with 25 indicators encompassing areas of mortality and morbidity, risk factors and national systems response. NCDs were identified as a priority for women's health and development in order to stimulate policy dialogue, in particular addressing issues that affect women, and to facilitate advances in informed action by all partners. This document identified entrenched poverty, gender inequality, the stigma associated with NCDs, women's family responsibilities and the cost of seeking care as significant barriers to accessing cost-effective prevention as well as the early detection, diagnosis, treatment and care of NCDs.

Globally, there are major differences between women and men with regard to the risk factors for CVD [53]. As seen in figure 1, women have an excess of hypertension, a lower smoking risk, a comparable risk due to dyslipidemia and obesity and a greater risk due to diabetes and psychosocial issues.
Wenger 


\section{Global Challenges and Opportunities}

As noted, CVD represents $38 \%$ of deaths from NCDs, $80 \%$ of which occur in low- and middle-income countries. It is estimated that between 2010 and 2020, the global prevalence of CVD will increase by $15-20 \%$. Much of this problem relates to the changes in lifestyle in developing nations that are unfavorable for cardiovascular health: urbanization, a Western diet and consumption of processed foods with consequent increases in obesity, hypertension, dyslipidemia and diabetes [53-55].

Between 1990 and 2020, there will be an estimated $120 \%$ increase in CVD mortality for women in developing countries, in contrast to a $29 \%$ increase among women in industrialized nations. Of the women who will die from CHD, $80 \%$ of the deaths will occur in low- and middle-income countries.

Importantly, in the INTERHEART study [26], modifiable risk factors accounted for $94 \%$ of the population-adjusted cardiovascular mortality in women. The recommended interventions are not costly. Both in the USA and globally, there is a need to educate the population, but women in particular, about CVD risk factors with an emphasis on the modifiable behavioral risk factors. Women should be informed that basic lifestyle modifications have the potential to decrease hypertension, dyslipidemia, obesity, diabetes and cardiovascular risk. Tantamount is smoking cessation, but also a diet low in sodium and saturated fats and more fruits and vegetables. An increase in exercise behavior is mandatory. Messages should be targeted at women, particularly in low- and middle-income nations. All organizations directed toward women's heart health should engage women on a community level as well as developing national risk reduction priorities. This is necessary to lessen the risk among women of CVD, myocardial infarction and sudden death.

At the 2013 World Health Assembly, CVD was identified as the largest killer of women worldwide, increasingly impacting women in developing countries. Very few women perceive CVD as the greatest threat to their health. Basic health interventions that educate people on healthy lifestyle choices can be effective in reducing mortality rates and risk factors associated with CVD. Poverty, however, limits women's ability to make healthy choices, making women in low- and middle-income countries living in poverty particularly vulnerable to CVD. As an example, the proportion of CVD deaths in women aged 35-44 years in South Africa is $150 \%$ higher than that for women in the USA. There is also a significant gender gap in the diagnosis and treatment of CVD in women. Warning signs for women differ from those for men, contributing to an underdiagnosis of CVD. More women-specific clinical research is needed to address this issue, as the majority of clinical CVD trials to date have been undertaken in men.

\section{References}

1 Shaw GB: Pygmalion. London, Constable and Company Ltd., 1914.

2 Congressional Record: 113th Congress, 2nd Session, USA, 2014.

-3 Ford ES, Ajani UA, Croft JB, et al: Explaining the decrease in U.S. deaths from coronary disease, 1980-2000. N Engl J Med 2007;356: 2388-2398.

4 Towfighi A, Zheng L, Ovbiagele B: Sex-specific trends in midlife coronary heart disease risk and prevalence. Arch Intern Med 2009;169: 1762-1766.

5 Go AS, Mozaffarian D, Roger VL, et al: Heart Disease and Stroke Statistics - 2014 update: a report from the American Heart Association. Circulation 2014;129:e28-e292.

6 6 Leifheit-Limson EC, Spertus JA, Reid KJ, et al: Prevalence of traditional cardiac risk factors and secondary prevention among patients hospitalized for acute myocardial infarction (AMI): variation by age, sex, and race. J Womens Health 2013;22:659-666.

7 Mosca L, Benjamin DJ, Berra K, et al: Effectiveness-based guidelines for the prevention of cardiovascular disease in women - 2011 update: a guideline from the American Heart
Association. Circulation 2011;123:12431262.

-8 Fraser A, Nelson SM, Macdonald-Walllis C, et al: Associations of pregnancy complications with calculated cardiovascular disease risk and cardiovascular risk factors in middle age: the Avon Longitudinal Study of Parents and Children. Circulation 2012;125:1367-1380.

-9 Wenger NK: Recognizing pregnancy-associated cardiovascular risk factors. Am J Cardiol 2014;113:406-409.

10 Bellamy L, Casas J-P, Hingorani AD, Williams DJ: Preeclampsia and risk of cardiovascular disease and cancer in later life: systematic review and meta-analysis. BMJ 2007;335: 974-977.

11 Ahmed R, Dunford J, Mehran R, et al: Preeclampsia and future cardiovascular risk among women. A review. J Am Coll Cardiol 2014;63:1815-1822.

12 WHO: Collaborative study of cardiovascular disease and steroid hormone contraception. Ischaemic stroke and combined oral contraceptives: results of an international, multicentre, case-control study. Lancet 1996;348:498505.
13 Lubianca JN, Faccin CS, Fuchs FD: Oral contraceptives: a risk factor for uncontrolled blood pressure among hypertensive women. Contraception 2003;67:19-24.

14 Shufelt CL, Bairey Merz CN: Contraceptive hormone use and cardiovascular disease. J Am Coll Cardiol 2009;53:221-231.

15 Tanis BC, Van den Bosch MAAJ, Kemmeren $\mathrm{JM}$, et al: Oral contraceptives and the risk of myocardial infarction. N Engl J Med 2001; 345:1787-1793.

16 Bushnell C, McCullough L: Stroke prevention in women: synopsis of the 2014 American Heart Association/American Stroke Association guideline. Ann Intern Med 2014;160: 853-857.

17 Udell JA, Lu H, Redelmeier DA: Long-term cardiovascular risk in women prescribed fertility therapy. J Am Coll Cardiol 2013;62: 1704-1712.

18 Moyer VA on behalf of the US Preventive Services Task Force: Menopausal hormone therapy for the primary prevention of chronic conditions: US Preventive Services Task Force recommendation statement. Ann Intern Med 2013;158:47-54.
Transforming CVD Prevention in Women 
19 Nelson HD, Walker M, Zakher B, et al: Menopausal hormone therapy for the primary prevention of chronic conditions: a systematic review to update the US Preventive Services Task Force recommendations. Ann Intern Med 2012;157:104-113.

-20 Writing Group for the Women's Health Initiative Investigators: Risks and benefits of estrogen plus progestin in healthy postmenopausal women. Principal results from the Women's Health Initiative randomized controlled trial. JAMA 2002;288:321-333.

21 The Women's Health Initiative Steering Committee: Effects of conjugated equine estrogen in postmenopausal women with hysterectomy. The Women's Health Initiative randomized controlled trial. JAMA 2004;291:1701-1712.

22 Hulley S, Grady D, Bush T, et al: Randomized trial of estrogen plus progestin for secondary prevention of coronary heart disease in postmenopausal women. Heart and Estrogen/ Progestin Replacement Study (HERS) research group. JAMA 1998;280:605-613.

23 Salmon JE, Roman MJ: Subclinical atherosclerosis in rheumatoid arthritis and systemic lupus erythematosus. Am J Med 2008;121 (10 suppl 1):S3-S8.

24 Zhang J, Chen L, Delzell E, et al: The association between inflammatory markers, serum lipids and the risk of cardiovascular events in patients with rheumatoid arthritis. Ann Rheum Dis 2014;73:1301-1308.

25 Chobanian AV, Bakris GL, Black HR, et al; the National High Blood Pressure Education Program Coordinating Committee: The Seventh Report of the Joint National Committee on Prevention, Detection, Evaluation, and Treatment of High Blood Pressure. The JNC 7 Report. JAMA 2003;289:2560-2572.

26 Yusuf S, Hawken S, Ounpuu S, et al; the INTERHEART Investigators: Effect of potentially modifiable risk factors associated with myocardial infarction in 52 countries (the INTERHEART study): a case-control study. Lancet 2004;364:937-952.

$\checkmark 27$ Hajjar I, Kotchen JM, Kotchen TA: Hypertension: trends in prevalence, incidence, and control. Annu Rev Public Health 2006;27: 465-490.

-28 Wolf HK,Tuomilehto J, Kuulasmaa K, et al: Blood pressure levels in the 41 populations of the WHO MONICA Project. J Hum Hypertens 1997;11:733-742.

29 Huxley RR, Woodward M: Cigarette smoking as a risk factor for coronary heart disease in women compared with men: a systematic review and meta-analysis of prospective cohort studies. Lancet 2011;378:1297-1305.

-30 Kalyani RR, Lazo M, Ouyang P, et al: Sex differences in diabetes and risk of incident coronary artery disease in healthy young and middleaged adults. Diabetes Care 2014;37:830-838.

-31 Wannamethee SG, Papacosta O, Lawlor DA, et al: Do women exhibit greater differences in established and novel risk factors between diabetes and non-diabetes than men? The British Regional Heart Study and British Women's Heart Health Study. Diabetologia 2012; 55:80-87.
32 Wexler DJ, Nathan DM, Grant RW, et al: Sex disparities in treatment of cardiac risk factors in patients with type 2 diabetes. Diabetes Care 2005;28:514-520.

33 Peters SAE, Huxley RR, Woodward M: Diabetes as risk factor for incident coronary heart disease in women compared with men: a systematic review and meta-analysis of 64 cohorts including 858,507 individuals and 28,203 coronary events. Diabetologia 2014; 57:1542-1551.

34 Peters SAE, Huxley RR, Woodward M: Diabetes as a risk factor for stroke in women compared with men: a systematic review and meta-analysis of 64 cohorts, including 775,385 individuals and 12,539 strokes. Lancet 2014;383:1973-1980.

35 Goff DC Jr, Lloyd-Jones DM, Bennett G, et al: 2013 ACC/AHA guideline on the assessment of cardiovascular risk: a report of the American College of Cardiology/American Heart Association Task Force on practice guidelines. Circulation 2014;129:S49-S73.

36 Stone NJ, Robinson JG, Lichtenstein AH, et al: 2013 ACC/AHA guideline on the treatment of blood cholesterol to reduce atherosclerotic cardiovascular risk in adults: a report of the American College of Cardiology/ American Heart Association Task Force on practice guidelines. Circulation 2014;129:S1S45.

-37 Eckel RH, Jakicic JM, Ard JD, et al: 2013 AHA/ACC guideline on lifestyle management to reduce cardiovascular risk: a report of the American College of Cardiology/ American Heart Association Task Force on practice guidelines. Circulation 2014; 129:S76-S99.

38 Kostis WJ, Cheng JQ, Dobrzynski JM, et al: Meta-analysis of statin effects in women versus men. J Am Coll Cardiol 2012;59:572-582.

- 39 Jensen MD, Ryan DH, Apovian CM, et al: 2013 AHA/ACC/TOS guideline for the management of overweight and obesity in adults: a report of the American College of Cardiology/American Heart Association Task Force on practice guidelines and the Obesity Society. Circulation 2014;129:S102-S138.

40 WHO: Global Status Report on Noncommunicable Disease 2010. Geneva, World Health Organization, 2011.

41 Manson JE, Rimm EB, Stampfer MJ, et al: Physical activity and incidence of non-insulin-dependent diabetes mellitus in women. Lancet 1991;338:774-778.

$42 \mathrm{Hu}, \mathrm{FB}$, Stampfer MJ, Solomon C, et al: Physical activity and risk for cardiovascular events in diabetic women. Ann Intern Med 2001; 134:96-105.

43 Shah, AJ, Ghasemzadeh N, Zaragoza-Macias E, et al: Sex and age differences in the association of depression with obstructive coronary artery disease and adverse cardiovascular events. J Am Heart Assoc 2014;3:e000741.

44 Lichtman JH, Froelicher ES, Blumenthal JA, et al; the American Heart Association Statistics Committee of the Council on Epidemiology and Prevention and the Council on Cardiovascular and Stroke Nursing: Depression as a risk factor for poor prognosis among patients with acute coronary syndrome: systematic review and recommendations: a scientific statement from the American Heart Association. Circulation 2014;129:1350-1369.

45 Rosengren A, Hawken S, Ounpuu S, et al; the INTERHEART Investigators: Association of psychosocial risk factors with risk of acute myocardial infarction in 11,119 cases and 13,648 controls from 52 countries (the INTERHEART study): a case-control study. Lancet 2004;364:953-962.

46 Rutledge T, Linke SE, Johnson BD, et al: Relationships between cardiovascular disease risk factors and depressive symptoms as predictors of cardiovascular disease events in women. J Womens Health 2012;21:133139.

47 Berger JS, Roncaglioni MC, Avanzini F, et al: Aspirin for the primary prevention of cardiovascular events in women and men. A sexspecific meta-analysis of randomized controlled trials. JAMA 2006;295:306-313.

48 Ridker PM, Cook NR, Lee I-M, et al: A randomized trial of low-dose aspirin in the primary prevention of cardiovascular disease in women. N Engl J Med 2005;352:12931304.

49 Mosca L, Mochari-Greenberger H, Dolor RJ, et al: Twelve-year follow-up of American women's awareness of cardiovascular disease risk and barriers to heart health. Circ Cardiovasc Qual Outcomes 2010;3:120-127.

50 Mosca L, Hammond G, Mochari-Greenberger $\mathrm{H}$, et al; the American Heart Association Cardiovascular Disease and Stroke in Women and Special Populations Committee of the Council on Clinical Cardiology, Council on Epidemiology and Prevention, Council on Cardiovascular Nursing, Council on High Blood Pressure Research and Council on Nutrition, Physical Activity and Metabolism: Fifteen-year trends in awareness of heart disease in women: Results of a 2012 American Heart Association national survey. Circulation 2013;127:1254-1263.

51 Mosca L, Mochari H, Christian A, et al: National study of women's awareness, preventive action, and barriers to cardiovascular health. Circulation 2006;113:525-534.

52 Framework Convention NCD Alliance: Global status report on noncommunicable diseases: a priority for women's health and development. Geneva, World Health Organization, 2010. http://www.who.int.nmh/events/un ncd_summit2011/en/.

53 Gupta D, Wenger NK: Guidelines for the prevention of cardiovascular disease in women international challenges and opportunities. Exp Rev Cardiovasc Ther 2012;10:379-385.

54 Yusuf S, Reddy S, Ounpuu S, et al: Global burden of cardiovascular diseases. I. General considerations, the epidemiologic transition, risk factors, and impact of urbanization. Circulation 2001; 104:2746-2753.

55 Chiuve SE, Fung TT, Rexrode KM, et al: Adherence to a low-risk, healthy lifestyle and risk of sudden cardiac death among women. JAMA 2011;306:62-69. 